\title{
RELAÇÕES ENTRE APRENDIZAGEM E DESENVOLVIMENTO EM PIAGET E EM VYGOTSKY: dicotomia ou compatibilidade?
}

\author{
Relationships between learning and development do \\ Piaget and to Vygotsky: dichotomy or compatibility
}

Marcilio Lira de Souza Filho

Mestre em Psicologia Cognitiva, Psicólogo do Tribunal Regional Eleitoral do Amapá, Amapá, AP - Brasil, e-mail: liradesouza@yahoo.com.br

\begin{abstract}
Resumo
O presente estudo teve como objetivo discutir acerca das relações entre a aprendizagem e o desenvolvimento, comparando as perspectivas de Jean Piaget e Lev Vygotsky e analisando a possível compatibilidade entre as duas posições teóricas. São demonstrados os diferentes enfoques dados por esses autores quando tratam da relação entre a aprendizagem e desenvolvimento. Enquanto Piaget centra-se no desenvolvimento maturacional, Vygotsky centra seus esforços na relevância da aprendizagem. Suas particularidades teóricas geralmente levam à equivocada conclusão de um conflito insolúvel entre suas posições. Sem defender uma complementaridade entre as teorias, argumenta-se a favor de uma visão não excludente ou estritamente dicotômica entre as duas abordagens, notadamente quando se lida com a realidade e mais especificamente em práticas de intervenção, como é o caso das situações escolares.
\end{abstract}

Palavras-chave: Piaget; Vygotsky; Aprendizagem; Desenvolvimento.

Este estudo contou com o apoio do CNPq (Conselho Nacional de Desenvolvimento Científico e Tecnológico). O autor também agradece as valiosas críticas e sugestões da Dr. Alina Galvão Spinillo.

Rev. Diálogo Educ., Curitiba, v. 8, n. 23, p. 265-275, jan./abr. 2008 


\section{Abstract}

The present study intends to discuss the relations between learning and development, comparing the perspectives of Jean Piaget and Lev Vygotsky, as well as analyzing possible compatibility between the two theoretical positions. We demonstrate the different focuses these two authors take when dealing with the relation between learning and development. While Piaget focuses on maturational development, Vygotsky's efforts are centered on the relevance of learning. Their theoretical particularities general lead to the erroneous conclusion that there is an insoluble conflict between their positions. Without defending any complementarity between the two theories, we argue for a non-excluding or strictly dichotomic view between the two approaches, especially when dealing with reality and, more specifically, intervention practices, as is the case in school situation.

Keywords: Piaget; Vygotsky; Learning; Development.

Uma das grandes áreas de interesse da psicologia é o estudo de como o pensamento se modifica ao longo da vida dos indivíduos. Os esforços relacionados ao desenvolvimento cognitivo buscam compreender como as habilidades mentais surgem e modificam-se em face da maturação biológica e da experiência ou aprendizagem (STERNBERG, 2000). Alguns desdobramentos emergem a partir dessa área de interesse. Uma questão premente são as possíveis relações que podem existir entre o desenvolvimento e a aprendizagem.

Spinillo (1999) aponta essa questão, segundo a qual se indaga a relação dos dois fenômenos (aprendizagem e desenvolvimento) em termos de suas influências mútuas, ou seja, seria o desenvolvimento um restritor das habilidades possíveis de serem adquiridas, estando o que poderia ser aprendido condicionado estritamente ao estágio desenvolvimental atingido? Ou teria a aprendizagem a propriedade de facilitar o desenvolvimento?

Este ensaio visa discutir as relações entre aprendizagem e desenvolvimento, comparando os posicionamentos teóricos distintos de Jean Piaget e Lev Vygotsky e analisando a possível compatibilidade entre seus modelos teóricos. Nos tópicos que seguem serão apresentados separadamente seus pontos vista sobre essa questão, onde se verá que em Piaget há uma maior ênfase no aspecto maturacional do desenvolvimento, enquanto que Vygotsky focaliza mais o papel da aprendizagem. Posteriormente, serão discutidas as possíveis comunalidades entre seus pólos teóricos.

Rev. Diálogo Educ., Curitiba, v. 8, n. 23, p. 265-275, jan./abr. 2008 
Relações entre aprendizagem e desenvolvimento em Piaget e em Vygotsky

\section{Jean Piaget: enfoque no desenvolvimento maturacional}

[...] a maturação consiste, essencialmente, em abrir possibilidades novas e constitui, portanto, condição necessária do aparecimento de certas condutas [...] (PIAGET; INHELDER, 1986, p. 130).

[...] a aprendizagem não se confunde necessariamente com o desenvolvimento [...]. (PIAGET; GRÉCO, 1974, p. 34).

De acordo com Turner (1976), três postulados são centrais para o entendimento do posicionamento de Jean Piaget. O primeiro diz respeito a que tal como toda entidade biológica tem uma organização interna, a cognição humana teria também uma organização característica. Em segundo lugar, a referida organização interna é responsável pelo modo único de funcionamento do organismo, sendo este invariante, ou seja, o mesmo tanto para uma criança quanto para uma pessoa idosa. Em terceiro lugar, Piaget defende que da interação entre o organismo e o ambiente, por meio dos invariantes modos de funcionamento, há uma adaptação das estruturas cognitivas (processo de adaptação), bem como o desenvolvimento delas (processo de organização).

Na perspectiva evolutiva de Piaget, o comportamento humano adulto, bem como seu aparato cognitivo não podem ser adequadamente compreendidos sem a perspectiva evolutiva (INHELDER; PIAGET, 1976). Ela compreende uma cuidadosa descrição e análise de estados ontogenéticos sucessivos. O dado mais importante são as modificações comportamentais de um funcionamento menos sofisticado para um mais sofisticado. Nesse sentido, formas específicas de respostas ou padrões de comportamentos suficientemente distintos seriam úteis para justificar a consideração de períodos ou estágios definidos de desenvolvimento (AULT, 1978). Assim, a teoria piagetiana indica a existência de quatro períodos principais que cobrem seqüencialmente o desenvolvimento cognitivo, a saber, sensório motor, o pré-operatório, o operatório concreto e o operatório formal. Todos os indivíduos evoluiriam obedecendo a essa seqüência invariante que compreende um maior grau de sofisticação na medida em que se avança na direção do último estágio.

Piaget (1970) defende que o desenvolvimento cognitivo é organizado e guiado por estruturas mentais compostas por "esquemas de ação" e "operações de caráter lógico-matemático". Inicialmente, tais estruturas são categorias inatas que vão amadurecendo e adquirindo natureza distinta por meio de um processo de "equilibração" entre o sujeito e seu ambiente. Como já comentado, o indivíduo seria dotado de funções adaptativas invariáveis ao longo da vida. Nessa adaptação intelectual estaria em jogo uma organizada e constante assimilação do novo ("conhecimento") ao velho e uma acomodação do velho ao novo que manteriam em

Rev. Diálogo Educ., Curitiba, v. 8, n. 23, p. 265-275, jan./abr. 2008 
equilibrio o funcionamento cognitivo. O desenvolvimento cognitivo, assim, é um processo de equilibrações sucessivas das estruturas cognitivas (esquemas). Estruturas estas que vão evoluindo com base na configuração da estrutura precedente.

Como é possível perceber, há um claro respaldo filosófico neokantiano nessa concepção. Aquilo que uma criança traz consigo, já desde o nascer, satisfaz o seu desenvolvimento. Piaget, inclusive, diferencia aprendizagem de maturação ao destacar que a maturação tem por base apenas processos fisiológicos inatos (PALANGANA, 1994). Por sua vez, a aprendizagem, as experiências, as interações, enfim, as situações concretas da vida e da educação contribuem para o desenvolvimento, entretanto, não são essenciais para que este aconteça, posto que não geram as qualidades mentais inatas que já existiam (PIAGET, 1973).

Um exemplo disso é o desenvolvimento da inteligência. Para Piaget (1970), seu desenvolvimento é advindo de processos naturais ou espontâneos. Ele pode até ser estimulado e acelerado pela educação familiar ou pela escola, mas a dependência dos mecanismos maturacionais é a condição prévia para a eficácia de qualquer aprendizado. Ele cita o caso dos oligofrênicos (ou portadores de deficiência mental, numa denominação mais atual) para os quais as melhores abordagens educativas são insuficientes para desenvolver a inteligência que lhes falta. Destarte, pode-se depreender que, para Piaget, a aprendizagem, em geral, exerce certa influência no desenvolvimento, porém, não o impulsionaria uma vez que não teria capacidade de criar novas competências.

Em resumo, de forma estrita, para Piaget o processo de desenvolvimento é independente dos processos conhecidos de aprendizagem (PIAGET GRÉCO, 1974) e sem maturação suficiente não há desenvolvimento (PIAGET, 1973). De acordo com ele, o conhecimento não é imanente nem ao sujeito, nem tampouco aos objetos, mas que são construídos a partir da interação entre ambos (PIAGET, 1973; PIAGET; GRÉCO, 1974). Não obstante, na medida em que postula que o desenvolvimento é decorrente dos mecanismos de adaptação e organização, ele incorpora fortemente, como já sugerido, elementos do inatismo em seu modelo (PALANGANA, 1994).

Neste contexto teórico, é marcante em Piaget sua não preocupação em explorar, de forma mais sistemática, outras variáveis antecedentes que pudessem catalisar ou retardar temporalmente o surgimento das diversas habilidades cognitivas (FLAVEL, 1975). A proposta de Lev Vygotsky, pelo contrário, centrase no empenho em demonstrar como outros elementos não maturacionais interferem no surgimento dessas habilidades.

\section{Lev Vygotsky: enfoque na aprendizagem}

[...] a aprendizagem não é, em si mesma, desenvolvimento, mas uma correta organização da aprendizagem da criança conduz ao desenvolvimento mental, ativa todo um grupo

Rev. Diálogo Educ., Curitiba, v. 8, n. 23, p. 265-275, jan./abr. 2008 
Relações entre aprendizagem e desenvolvimento em Piaget e em Vygotsky

de processos de desenvolvimento, e esta ativação não poderia produzir-se sem a aprendizagem. Por isso, a aprendizagem é um momento intrinsecamente necessário e universal, para que se desenvolvam na criança essas características humanas não naturais, mas formadas historicamente (VYGOTSKY, 1998, p. 115).

"De fato, aprendizado e desenvolvimento estão inter-relacionados desde o primeiro dia de vida da criança" (VYGOTSKY, 1984, p. 110).

Diversamente a Piaget, Vygotsky não formulou uma concepção estruturada do desenvolvimento humano, por meio da qual se pudesse interpretar ou mesmo situar o desenvolvimento cognitivo ao longo das etapas da vida (OLIVEIRA, 1997). Vygotsky (1988) toma como um de seus pressupostos básicos a idéia de que o ser humano constitui-se enquanto tal em relação com os demais (e aqui a linguagem assume um status de centralidade). Nesse sentido, a cultura compõe a natureza humana num processo histórico que, ao longo do desenvolvimento filogenético e ontogenético, molda o funcionamento psicológico humano.

Ao estudar a filogenia humana, um dos pontos de partida principais do desenvolvimento ontogenético, Vygotsky interessou-se por diferentes teorias biológicas evolutivas, como a de Charles Darwin; pelos clássicos experimentos primatológicos de Wolfgang Kohler; pela zoopsicologia de Vladmir Vagner; pelas análises da anatomia cerebral realizada por Edinger e Kretschemer; entre outros (VAN DER VEER; VALSINER, 1991). Todos esses são exemplos de fontes teóricas que denotam a importância dada ao substrato biológico-material em seu modelo teórico. Entretanto, não é a esse aspecto que Vygotsky centra-se para explicação do desenvolvimento, como será visto adiante.

Um conceito fundamental para a compreensão do progresso cognitivo humano em Vygotsky (1984) é a zona de desenvolvimento proximal. Este se refere ao percurso que faz um indivíduo para desenvolver funções que se encontram em processo de amadurecimento e que mais adiante se tornarão funções consolidadas, estabelecendo assim o nível de desenvolvimento real do indivíduo. Por exemplo, num dado momento, para executar uma atividade, uma criança pode necessitar do auxílio de um adulto ou de uma criança mais velha (habilidade situada em uma zona de desenvolvimento proximal), mas no futuro a criança será capaz de realizar a tarefa sozinha (habilidade situada em uma zona de desenvolvimento real). Ao que parece, o processo do desenvolvimento evoluiria mais lentamente que o da aprendizagem; a aprendizagem despertaria os processos de desenvolvimento que, paulatinamente, tornar-se-iam parte das funções psicológicas já firmadas no indivíduo.

De acordo com Vygotsky (1984), o aprendizado é capaz de gerar zonas de desenvolvimento proximal. Ao interagir com as pessoas em seu ambiente

Rev. Diálogo Educ., Curitiba, v. 8, n. 23, p. 265-275, jan./abr. 2008 
e/ou quando atuam em cooperação com seus pares, os processos internos de desenvolvimento são capazes de operar, uma vez que foram deflagrados pela aprendizagem. Nessa direção, a capacidade de desenvolvimento potencial das crianças está fortemente ligada às diferenças qualitativas no ambiente social das quais fazem parte (PALANGANA, 1994).

Aqui a relação entre aprendizagem e desenvolvimento é concebida sob uma ótica diferente. Não é o desenvolvimento que precede e torna possível a aprendizagem, mas é a aprendizagem que antecede, possibilita e impulsiona o desenvolvimento. Caso uma criança não venha a ter contato com adultos ou com outras crianças mais velhas, enfim, com quem possa lhe fornecer experiências que proporcionem a criação de competências e aptidões, esta criança não poderá desenvolver-se humanamente, isto é, a manifestação das chamadas funções psicológicas superiores (consciência, intenção, planejamento, entre outras) não se dará (VYGOTSKY, 1981). Isso indica que em situações nas quais não houver aprendizagem, não poderá ocorrer desenvolvimento.

Para Vygotsky (1984), o caminho do desenvolvimento humano é tanto definido pelos processos de maturação do organismo individual, concernente às contingências filogenéticas dos humanos, quanto pela aprendizagem que desperta os processos internos do desenvolvimento. Aprendizagem essa que, não fosse a interação com os demais, bem como o contato com o ambiente cultural, não poderia ocorrer.

O homem, como aponta Oliveira (2000), já nasce munido com características que são próprias de sua espécie, como, por exemplo, as funções processuais sofisticadas, que têm por base a atividade cortical, a possibilidade de enxergar através de dois olhos, o que permite uma percepção tridimensional da realidade, seu aparelho fonador capaz de emitir diferentes sons. Esses e outros equipamentos biológicos, entretanto, não são capazes, por si só, de gerar as funções psicológicas superiores, eles dependem fundamentalmente dos processos de aprendizagem.

Nesse sentido, para Vygotsky (1984), o aprendizado está profundamente relacionado com o desenvolvimento. Embora haja um processo de maturação do qual depende o organismo para se desenvolver, é o aprendizado que possibilita o despertar de processos internos de desenvolvimento (OLIVEIRA, 1997). As potencialidades inatas seriam condições capitais para o desenvolvimento do indivíduo, entretanto não seriam o bastante, uma vez que essas potencialidades não teriam força motora em relação a esse desenvolvimento.

Em resumo, poderia se afirmar que, de maneira geral, enquanto Vygotsky considera o desenvolvimento cognitivo "de fora para dentro", Piaget o veria de forma inversa, "de dentro para fora" (STERNBERG, 2000). Dito de forma mais clara, implicaria em dizer que Vygotsky focaliza as funções do ambiente

Rev. Diálogo Educ., Curitiba, v. 8, n. 23, p. 265-275, jan./abr. 2008 
Relações entre aprendizagem e desenvolvimento em Piaget e em Vygotsky

no desenvolvimento intelectual, ao advogar que a aprendizagem interage com o desenvolvimento, gerando seu avanço nas zonas de desenvolvimento proximal, onde as interações sociais e o contexto sociocultural são elementos essenciais. Por seu turno, Piaget defende que o desenvolvimento cognitivo se dá por meio do amadurecimento das estruturas lógicas (esquemas mentais), decorrente de processos endógenos de equilibração que precedem e limitam a aprendizagem, o que leva a concluir que as intervenções sociais atuariam como facilitadores do desenvolvimento, mas não determinantes de primeira ordem, lugar que estaria reservado para maturação dos esquemas.

Essas particularidades teóricas podem rapidamente levar a conclusão de que haveria um "conflito irredutível" entre Piaget e Vygotsky, o que parece ter sido comum entre teóricos e profissionais da educação no contexto latinoamericano (CASTORINA, 1995). Mas, realmente, até que ponto seus pontos de vista sobre a questão entre desenvolvimento e aprendizagem são tão díspares? No tópico seguinte serão tecidas algumas considerações a esse respeito.

\section{Piaget e Vygotsky: dicotomia ou compatibilidade?}

[...] existem limites maturacionais que condicionam, em certo sentido, aquilo que pode ser ensinado à criança. Ao mesmo tempo, há evidencias de que os efeitos da aprendizagem sobre o desenvolvimento cognitivo não podem ser entendidos como mero acaso. Ao que parece, nenhuma dessas perspectivas, se tomadas ao extremo, fornece interpretações adequadas acerca das possibilidades de mudanças no curso do desenvolvimento a partir da aprendizagem. (SPINILLO, 1999, p. 57).

A comparação entre os dois modelos teóricos acima descritos leva à visualização de abordagens distintas sobre o indivíduo, a aprendizagem, o desenvolvimento e as relações entre aprendizagem e desenvolvimento. De acordo com Palangana (1994), tanto Piaget quanto Vygotsky explicam a relação entre aprendizagem e desenvolvimento baseados em princípios interacionistas. Ambos diferem na medida em que Piaget (1973) tende a supervalorizar as funções do sujeito na construção do conhecimento ao enfocar a dimensão maturacional e Vygotsky (1984) destaca as relações dialéticas de construção do mesmo conhecimento quando supervaloriza o papel da interação e da aprendizagem. Em função disso, destaca-se o fato de, recorrentemente, ser atribuído à Piaget o termo de construtivista e à Vygotsky ser reservado a denominação de socioconstrutivista (BANKS LEITE, 1994).

Rev. Diálogo Educ., Curitiba, v. 8, n. 23, p. 265-275, jan./abr. 2008 
Considerado tudo o que foi comentado até o momento, cabe perguntar se seria realmente plausível pensar que essas duas perspectivas teóricas se situariam de forma estritamente oposta ou, ainda, se não poderia haver a possibilidade de configurá-las de forma a não parecerem antagônicas no que tange, em particular, à relação entre desenvolvimento e aprendizagem.

Como é possível perceber nos tópicos precedentes, não seria correto ou mesmo ingênuo afirmar que Piaget negou terminantemente a importância da aprendizagem ou da interação social para o desenvolvimento cognitivo. Bem como que Vygotsky não percebia as restrições biológicas ou maturacionais para o progresso do desenvolvimento. Fazer colocações como estas seria incorrer em um estrito e incoerente maniqueísmo.

La Taille (1992) argumenta, por exemplo, que seria injusto crer que Piaget desprezou o papel dos fatores sociais para o desenvolvimento humano. Tal posicionamento fica evidente em algumas passagens das obras de Piaget. Apenas para citar um exemplo, quando Piaget (1970, p. 47) diz que "além dos fatores de maturação e de experiência, a aquisição dos conhecimentos depende naturalmente das transmissões educativas ou sociais [...]" ele claramente considera como importante os fatores sociais. Desde o ponto de vista de La Taille (1992), Piaget não se deteve nessa questão, mas buscou situar as influências e determinações da interação sobre o desenvolvimento da inteligência.

Neste mesmo sentido, Vygotsky (1998, p. 111) afirma textualmente que é de "[...] comprovação empírica, freqüentemente verificada e indiscutível, que a aprendizagem deve ser coerente com o nível de desenvolvimento da criança". Para este autor não seria necessário realizar grandes demonstrações para comprovar que em determinadas idades não se pode aprender determinados conhecimentos. Ao prosseguir neste raciocínio, conclui que "[...] podemos tomar tranquilamente como ponto de partida o fato fundamental e incontestável de que existe uma relação entre determinado nível de desenvolvimento e a capacidade potencial de aprendizagem" (VYGOTSKY, 1998, p. 111). Essa passagem, bastante explícita, demonstra que Vygotsky, em absoluto, não deixava de perceber os comprometimentos maturacionais para evolução do desenvolvimento.

Piaget e Vygotsky, cada um a sua maneira, são necessariamente compatíveis quando se lida com a realidade, especificamente em práticas de intervenção, como é o caso da escola, por exemplo (SHAYER, 1997). Na prática, como geralmente se tende a não facilmente aceitar, ser pró-Vygotsky não implica, necessariamente, em ser anti-piagetiano (CASTORINA, 1995; SHAYER, 1997).

Nessa mesma direção, cabe lembrar evidências diversas de pesquisas, como assinala Spinillo (1999), que mostram que há limites maturacionais que restringem, de algum modo, aquilo que se pode aprender. E, por outro lado, os efeitos da aprendizagem sobre o desenvolvimento de determinadas habilidades

Rev. Diálogo Educ., Curitiba, v. 8, n. 23, p. 265-275, jan./abr. 2008 
Relações entre aprendizagem e desenvolvimento em Piaget e em Vygotsky

não podem ser consideradas como casuais. Aprendizagem e desenvolvimento, portanto, relacionar-se-iam de maneira circular. É possível concluir, assim, que se desenvolve mais quem melhor aprende e quanto mais se aprende mais facilitado torna-se o processo de desenvolvimento.

Como se pode ver, tanto Piaget quanto Vygotsky consideram a existência de restrições biológicas, muito embora o apriorismo ou inatismo seja mais enfocado pelo primeiro. Não obstante, ambos também julgam importante o papel das experiências e interações sociais, mas em Vygotsky esses elementos são mais assinalados. Dessa forma, a questão não é a desconsideração da maturação ou da experiência, mas sim o enfoque maior sobre um ou outro aspecto que pode proporcionar uma aparente contradição entre seus posicionamentos no que tange à relação entre aprendizagem e desenvolvimento.

Considerando tais aspectos, as duas abordagens aqui tratadas não deveriam ser consideradas como excludentes ou estritamente dicotômicas. Antes disso, devem ser tidas como compatíveis na medida em que são trabalhos que não negam absolutamente o ponto de vista um do outro. Não se trata, todavia, de uma complementaridade entre teorias.

Em sua reflexão por ocasião da comemoração do centenário de nascimento de Piaget e Vygotsky, Bruner (1997) postula a incomensurabilidade entre as teorias piagetiana e vygotskyana. Para este autor, seria ingênua uma tentativa de combinar num sistema único as duas perspectivas e conclui asseverando que cada perspectiva caminha independentemente. Não obstante, o que se postula aqui é uma compatibilidade entre idéias específicas referentes a um ponto particular entre as teorias, ou seja, entre as relações da aprendizagem e do desenvolvimento. Não se trata aqui de efetuar uma "reconciliação fácil" como poderia antecipar o próprio Bruner (1997).

Mesmo Bruner (1997) reconhece que os dois modelos teóricos, apesar de serem distintos e irredutíveis, possuem uma anômala e desafiadora relação mútua. Isso não é de maneira alguma casual. Ora, ambas buscam contemplar o mesmo fenômeno - o progresso cognitivo - e é mais do que razoável propor que haja pontos de comunalidades. As aparentes contradições teóricas se devem, basicamente, a um enfoque maior em um ou outro elemento (maturação ou aprendizagem), sem, contudo, haver uma negação excludente daquele elemento não enfocado.

Castorina (1995) aponta que existem algumas diferenças no interesse investigativo central de Piaget e Vygotsky. Enquanto Piaget está preocupado com a psicogênese, ou seja, com os mecanismos responsáveis por fazer com que o indivíduo evolua de um estado de menor conhecimento para um de maior conhecimento, Vygotsky buscava saber como as funções psicológicas naturais ou primárias constituíam-se em funções psicológicas superiores a partir da utilização das ferramentas culturais adquiridas pela aprendizagem.

Rev. Diálogo Educ., Curitiba, v. 8, n. 23, p. 265-275, jan./abr. 2008 
Uma vez que se concebe que a equilibração fornece uma explicação para como o sujeito e o objeto de conhecimento são construídos e que a formação dos conhecimentos pode ser entendida como a adoção ou internalização dos instrumentos culturais ao longo do desenvolvimento ontogenético, percebe-se o quão útil seria articular os dois níveis de explicação (CASTORINA, 1995). Isso justificaria adotar a visão de uma relação de compatibilidade entre as teorias ao se lidar com a realidade empírica, posto que, como já comentado, nenhuma implicaria a adoção ou rejeição da outra.

\section{REFERÊNCIAS}

AULT, R. L. Desenvolvimento cognitivo da criança: a teoria de Piaget e a abordagem de processo. Rio de Janeiro: Zahar, 1978.

BRUNER, J. S. Celebrating divergence: Piaget and Vygotsky. Human Development, Chicago, v. 40, n. 2, p. 63-73, 1997.

BANKS LEITE, L. As interações sociais na perspectiva piagetiana. Série Idéias, São Paulo, v. 20, p. 41-47, 1994.

CASTORINA, J. A. O debate Piaget-Vygotsky - A busca de um critério para sua avaliação. In: CASTORIANA, J. A. et al. (Ed.). Piaget-Vygotsky: novas contribuições para o debate. São Paulo: Ática, 1995. p. 7-50.

FLAVEL, J. H. A psicologia do desenvolvimento de Jean Piaget. São Paulo: Pioneira, 1975.

INHELDER, B.; PIAGET, J. Da lógica da criança à lógica do adolescente. São Paulo: Pioneira, 1976.

LA TAILLE, Y. O lugar da interação social na concepção de Jean Piage. In: LA TALILLE, Y.; OLIVEIRA, M. K.; DANTAS, H. (Org.). Piaget, Vygotsky e Wallon: teorias psicogenéticas em discussão. 13. ed. São Paulo: Sammus, 1992. p. 47-74.

OLIVEIRA, M. K. Vygotsky: aprendizado e desenvolvimento: um desenvolvimento sócio-histórico. São Paulo: Scipione, 1997.

Pensar a educação: contribuições de Vygotsky. In: CASTORINA, J. A., LERNER, E. F. D.; OLIVEIRA, M. K. (Org.). Piaget e Vygotsky: novas contribuições para o debate. São Paulo: Ática, 2000. p. 51-83.

PALANGANA, I. C. Desenvolvimento e aprendizagem em Piaget e Vygotsky: a relevância do social. São Paulo: Plexus, 1994. 
PIAGET, J. Psicologia e pedagogia. Rio de Janeiro: Forense, 1970.

. Psicologia e epistemologia: por uma teoria do conhecimento.

Rio de Janeiro: Forense, 1973.

PIAGET, J.; GRECO, P. Aprendizagem e conhecimento. Rio de Janeiro: Freitas Bastos, 1974.

PIAGET, J.; INHELDER, B. A psicologia da criança. São Paulo: Difusão, 1986.

SHAYER, M. Piaget and Vygotsky: a necessary marriage for effective educational intervention. In: SIMITH, L.; DOCKRELL, J.; TOMLISON, P. (Org.). Piaget, Vygotsky and beyond: future issues for develompmental psychology and education. London: Routledge, 1997. p. 36-59.

SPINILLO, A. G. As relações entre aprendizagem e desenvolvimento discutidas a partir de pesquisas de intervenção. Arquivos Brasileiros de Psicologia, v. 51, n. 1, p. 55-74, 1999.

STERnBERG, R. J. Psicologia cognitiva. Porto Alegre: Artes Médicas, 2000.

TURNER, J. Desenvolvimento cognitivo. Rio de Janeiro: Zahar, 1976.

VAN DER VEER, R.; VALSINER, J. Vygotsky: uma síntese. São Paulo: Loyola, 1991.

VYGOTSKY, L. S. The genesis of higher mental functions. In: WERTSCH, J. V. (Org.). The concept of activity in soviet psychology. Nova York: Sharpe, 1981. p. 134-143.

A formação social da mente. São Paulo: Martins Fontes, 1984.

. Pensamento e linguagem. São Paulo: Martins Fontes, 1988.

. Aprendizagem e desenvolvimento intelectual na idade escolar.

In: VYGOTSKY, L. S.; LURIA, A. R.; LEONTIEV, A. N. (Org.).

Linguagem, desenvolvimento e aprendizagem. São Paulo: Ícone, 1998. p. 103-117.

Recebido: 21/03/2007

Received: 03/21/2007

Aprovado: 28/07/2007

Approved: 07/28/2007

Rev. Diálogo Educ., Curitiba, v. 8, n. 23, p. 265-275, jan./abr. 2008 